\title{
LAPAROSCOPIC TREATMENT OF POLAND'S SYNDROME USING THE OMENTUM FLAP TECHNIQUE
}

\author{
Sirlei Santos Costa, ${ }^{\text {I }}$ Rosa Maria Blotta, ${ }^{\mathrm{I}}$ Mirandolino Batista Mariano, ${ }^{\mathrm{II}}$ Luise Meurer, ${ }^{\mathrm{III}}$ Maria Isabel Albano Edelweiss ${ }^{\mathrm{III}}$
}

doi: $10.1590 / \mathrm{S} 1807-59322010000400009$

Costa SS, Blotta RM, Mariano MB, Meurer L, Edelweiss MIA. Laparoscopic treatment of poland's syndrome using the omentum flap technique. Clinics. 2010;65(4):401-6.

OBJECTIVE: For patients with Poland's syndrome, a transverse skin fold in the anterior axillary pillar, infra-clavicular depression and an anomalous breast contour are the most uncomfortable disfigurements. This study aims to demonstrate that superior aesthetic results can be achieved by using a laparoscopically harvested omentum flap to treat this condition.

METHODS: From a prospectively maintained clinical database of patients undergoing a laparoscopic omentum flap procedure for breast reconstruction, all of the patients with Poland's syndrome were identified and their outcomes were studied.

RESULTS: Thirteen consecutive patients with Poland's syndrome were treated and evaluated regarding breast contour, reconstruction of the anterior axillary pillar and filling of the infra-clavicular depression. Implants were employed beneath the flap in $76 \%$ of cases to improve symmetry. In $23 \%$ of cases, a contra-lateral mastopexy was performed, and in $15 \%$ of cases, a breast implant was used. The consistency of the flap is similar to natural breast tissue and only a small incision in the breast fold is needed. The majority of patients (85\%) were female, with a mean age of 26 (18-53). The flap is extremely malleable, adapts to irregular surfaces, and has a long vascular pedicle. Additionally, its removal does not leave a scar at the donor site as the removal of muscular flaps does. For example, the removal of the latissimus dorsi flap causes a deformity in the dorsal contour. The mean operative time was 201 minutes (80-350) and the mean hospital stay was 2.3 days (1-5).

CONCLUSIONS: The outcomes of these patients revealed that the omentum flap technique provided superior amelioration of the deformities caused by Poland's syndrome when compared with other reconstructive options.

KEYWORDS: Poland's syndrome; Omentum flap; Breast deformities; Laparoscopically harvested omentum flap; Breast asymmetry.

\section{INTRODUCTION}

In 1841, Alfred Poland presented a 27-year-old patient with unilateral pectoralis major muscle absence and syndactyly on the same side. ${ }^{2}$ However, Poland's syndrome received its name only after Clarkson treated a similar patient in 1962., ${ }^{1,2}$ Patients with Poland's syndrome may present with numerous ailments, such as absence of the

\footnotetext{
${ }^{\text {I }}$ Department of Surgery, Universidade Federal do Rio Grande do Sul - Rio Branco/PA, Brazil.

II Hospital Moinhos de Vento - Moinhos de Vento/PA, Brazil.

III Department of Pathology, Hospital de Clínicas de Porto Alegre, Universidade Federal do Rio Grande do Sul - Rio Branco/PA, Brazil.

Tel.: 55513333.9409

Email: sirlei@sirleicosta.com.br

Received for publication on January 26, 2010

First review completed on January 29, 2010

Accepted for ublication on January 29, 2010
}

sternal-costal portion of the pectoralis major muscle, upper extremity hypoplasia, brachysyndactyly, and syndactyly. Various other muscles may also be affected, including the pectoralis minor, the latissimus dorsi, the serratus anterior, the external oblique, and the deltoid. Skeletal deformities such as partial agenesis of the ribs, sternum, and spine (sometimes with scoliosis) may occur. Other features of Poland's syndrome include breast hypoplasia or aplasia, nipple abnormalities, skin atrophy, and the absence of sweat glands and surrounding structures. . $^{1,3,4}$

In Poland's syndrome, the thoracic wall deformities are not as obvious at birth as the hand deformities. However, when female patients reach adolescence, the thoracic deformity often becomes more evident as absent or asymmetrical breast development occurs. To minimize this effect, a tissue expander may be placed in the developing breast to mimic the growth of the contra-lateral breast. 
Unfortunately, surgical treatment of the breast deformities cannot be accomplished before 17-19 years of age when development of the body is complete.

For patients with Poland's syndrome, some of the most uncomfortable physical disfigurements are the transverse skin fold in the anterior axillary pillar, which is caused by absence or hypoplasia of the pectoral muscles, the infraclavicular depression, and an anomalous breast contour. ${ }^{5}$ The resulting aesthetic derangement is difficult to hide, leads to thoracic asymmetry, and imposes significant psychological trauma and social withdrawal in both men and women.

Various options have been proposed to restore the breast's volume, including expanders and implants, transposition of the latissimus dorsi muscle flap (when unaffected by the syndrome), and use of the rectus abdominis muscle flap when the latissimus dorsi is absent. ${ }^{5-8}$ While these techniques may achieve excellent results depending on the degree of deformity, satisfaction with the aesthetic reconstruction of the anterior axillary pillar and the filling of the infraclavicular depression has been low. ${ }^{5}$ Moreover, the use of those muscular flaps generates an additional scar in the patient's donor region. In addition to a scar, removal of the latissimus dorsi flap also leaves an additional deformity in the dorsal contour due to the absence of muscle filling the posterior axillary pillar. In addition to being unsightly, it can be very uncomfortable when wearing certain clothes (Figure 1).

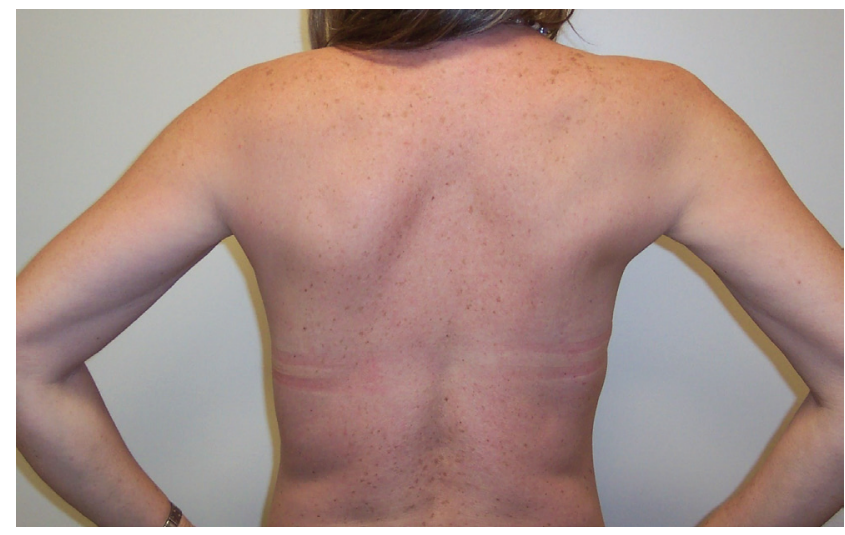

Figure 1 - A latissimus dorsi flap deformity of the right side. Although subtle, this difference can be very uncomfortable when wearing certain clothes.

As a way to alleviate these problems, a laparoscopically harvested omentum flap should be considered because it is an excellent reconstructive option that offers superior aesthetic results in Poland's syndrome cases. ${ }^{9}$

\section{SUBJECTS AND METHODS}

This is a temporal historical series with descriptive characteristics regarding cases of Poland's syndrome.

Since 1996, 51 patients with breast deformities have been treated by transposition of the omentum flap harvested using video laparoscopy at our institution. Of these, 13 had Poland's syndrome and presented with severe hypomastia and agenesis of the pectoralis major muscle. In all of the 13 patients treated, the anterior axillary pillar was absent, there was an infra-clavicular depression that resulted in an evident anterior thoracic wall asymmetry, and it was determined that the local tissues were insufficient to adequately cover the implant chosen for breast volume reconstruction.

These patients were treated by a single surgeon (one of the authors, S.S. Costa) over the 12-year study period. During this time, many improvements to the surgical tools and imaging technologies have been incorporated into the technique, but the basics of the protocol remain the same. In the absence of specific contraindications to laparoscopy, patients were considered candidates for transposition of the omentum flap harvested using video laparoscopy to treat these deformities in the breast and thoracic wall. Previous procedures (surgery, radiotherapy or infection) that had removed or compromised the viability of the omentum were considered absolute contraindications.

All patients were informed about the risks of the laparoscopic procedure and selected it based on the perceived risk-benefit ratio.

\section{Surgical Technique for Harvesting the Omentum Flap}

The procedure to harvest the omentum flap is performed using standard laparoscopic surgery techniques. Four ports are placed as usual, and a $\mathrm{CO}_{2}$ pneumoperitoneum of $8-10 \mathrm{mmHg}$ is maintained during the procedure (Figure 2). Dissection of the flap is initiated by clamping and elevating the gastric wall. The right gastro-epiploic artery is isolated and preserved; ligations of the short gastric arteries along the greater curvature are then performed until the left gastro-epiploic artery is reached. The omentum should be disconnected from the transverse colon by a

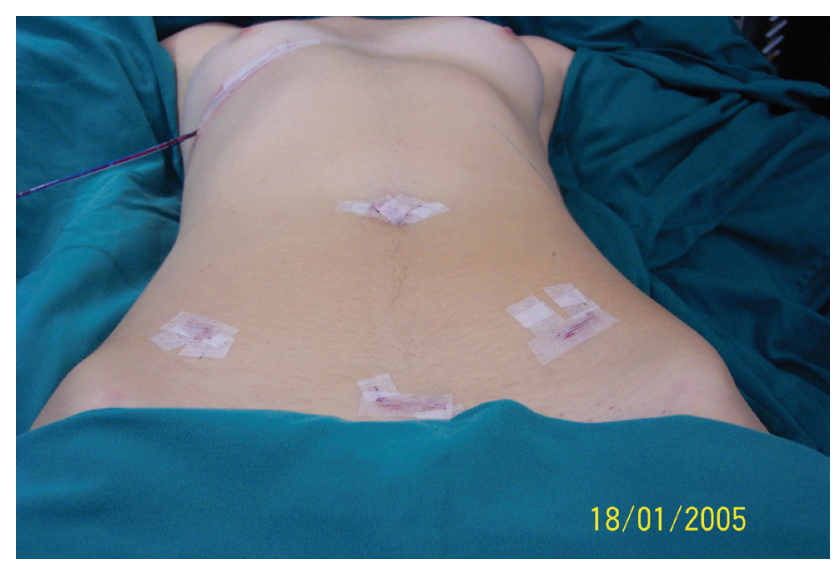

Figure 2 - Four ports are usually used to harvest the omentum flap. 


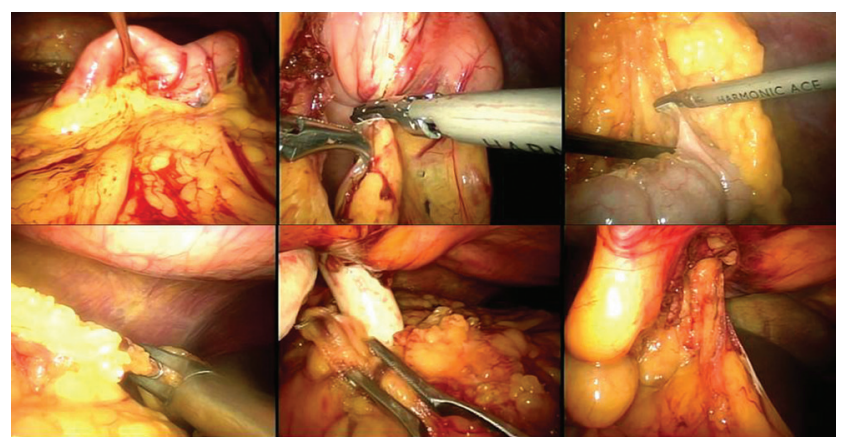

Figure 3 - From left to right, elevation of the gastric wall, ligations of the short gastric arteries, liberation of the colon segment, ligation of the left gastro-epiploic artery, incision in the peritoneum to pull the omentum flap (using a finger maneuver) from the abdominal cavity to the breast region.

careful dissection in order to preserve the vascularity of the mesocolon. The flap is sufficiently liberated when ligations of the left gastro-epiploic artery are accomplished adjacent to the left colic flexure (Figure 3).

Finally, through a small incision in the infra-mammary fold, a subcutaneous tunnel is dissected up to the costal border to open the aponeurose in the medial line toward the abdominal cavity (Figure 3). This tunnel is placed to the left or right side of the round ligament depending on the site that needs reconstruction. Using a digital maneuver, the omentum is pulled from the abdominal cavity to the breast region to permit passage and placement of the flap over the specific thoracic wall region (Figures 3, 4). The location of the deformity is then dissected and filled in with the omentum flap, which is fixed into place. Both procedures are performed under video assistance.

\section{RESULTS}

Age, gender (M/F), side of the syndrome, use of complementary prosthesis in the breast, and time required

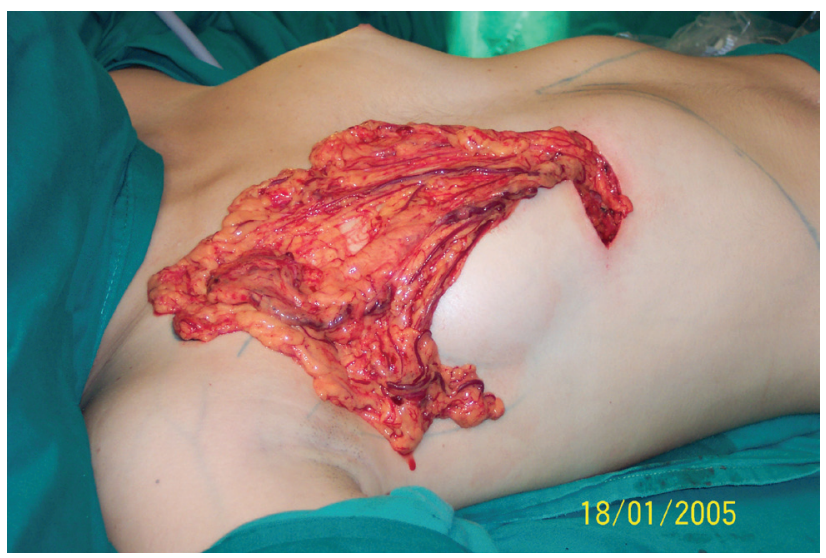

Figure 4 - The omentum flap on the thoracic wall.

for the laparoscopic dissection of the flap are shown in Table 1.

The majority of patients ( $85 \%$ ) were female with a mean age of 26 (18-35). There was no predominance in the side the disease had affected. To complement breast volume and achieve symmetry, $76 \%$ of the patients received an ipsilateral silicone prosthesis.

The mean operative time required for flap laparoscopic dissection in this group was 201 minutes (80-390).

\section{Short-Term Outcomes}

The mean hospital stay was 2.3 (range 1-5) days, and the patients resumed normal activities depending on individual treatment progress. Eight patients had post-prandial discomfort and moderate gastric distension with spontaneous regression occurring within 48 hours of the procedure.

Additionally, mastopexy (23\%), reduction (8\%) and augmentation procedures (15\%) of the contra-lateral breasts were performed on six patients to finalize the equalization of both breasts (Table 2). In 54\% of the patients, there was

Table 1 - Clinical and surgical characteristics of patients with Poland's syndrome in chronological order of their treatment.

\begin{tabular}{lccccc}
\hline Patient & Age & Gender & Side & Complementary prosthesis in the affected side & Operative time $(\mathrm{min})$ \\
\hline 1 & 18 & $\mathrm{~F}$ & $\mathrm{~L}$ & Yes & 360 \\
2 & 19 & $\mathrm{~F}$ & $\mathrm{R}$ & Yes & 390 \\
3 & 19 & $\mathrm{~F}$ & $\mathrm{R}$ & Yes & 330 \\
4 & 19 & $\mathrm{M}$ & $\mathrm{R}$ & No & 220 \\
5 & 18 & $\mathrm{~F}$ & $\mathrm{~L}$ & Yes & 290 \\
6 & 37 & $\mathrm{~F}$ & $\mathrm{R}$ & Yes & 190 \\
7 & 21 & $\mathrm{~F}$ & $\mathrm{R}$ & Yes & 190 \\
8 & 24 & $\mathrm{~F}$ & $\mathrm{R}$ & No & 160 \\
9 & 38 & $\mathrm{~F}$ & $\mathrm{~L}$ & Yes & 90 \\
10 & 53 & $\mathrm{~F}$ & $\mathrm{~L}$ & Yes & 100 \\
11 & 23 & $\mathrm{~F}$ & $\mathrm{~L}$ & Yes & 110 \\
12 & 35 & $\mathrm{~F}$ & $\mathrm{R}$ & Yes & 80 \\
13 & 25 & $\mathrm{M}$ & $\mathrm{R}$ & No & 110 \\
\hline
\end{tabular}


Table 2 - Short-term outcomes for thirteen patients with Poland's syndrome treated with the omentum flap procedure.

\begin{tabular}{lccc}
\hline Patient & $\begin{array}{c}\text { Post-prandial } \\
\text { discomfort }\end{array}$ & $\begin{array}{c}\text { Hospital stay } \\
\text { (days) }\end{array}$ & $\begin{array}{c}\text { Contra-lateral breast } \\
\text { intervention }\end{array}$ \\
\hline 1 & Yes & 2 & - \\
2 & Yes & 3 & Mastopexy \\
3 & Yes & 2 & Mastopexy \\
4 & No & 2 & - \\
5 & No & 1 & Prosthesis \\
6 & Yes & 2 & - \\
7 & No & 2 & Prosthesis \\
8 & No & 3 & Breast reduction \\
9 & Yes & 5 & - \\
10 & Yes & 2 & - \\
11 & Yes & 3 & Mastopexy \\
12 & No & 2 & - \\
13 & Yes & 2 & - \\
\hline Mean & & $2.3(1-5)$ & \\
\hline
\end{tabular}

no need for a procedure involving the other breast because the patient was satisfied with the initial result. There were no conversions to open procedures and no deaths. Blood loss was insignificant in all cases.

There were no significant intraoperative complications, such as omentum unavailability because of adhesions or small size, vascular injury or bowel injury. There were no cases of wound infection, internal hernia, loss of the flap or fat necroses during the postoperative period.

All of the patients with Poland's syndrome treated using the omentum flap procedure achieved a final aesthetic result better than that observed in patients who were treated with other techniques before this new option was available, as shown in Figure 5. By using the omentum flap, it is possible to correct particular details of the breast's contour due to the malleability of the flap tissue, an outcome that is impossible to achieve with any other technique. Utilization of the omentum flap improves breast contouring, the filling in of the infra-clavicular depression and the reconstruction of the anterior axillary pillar. When an implant is employed below the flap, it provides appropriate concealment and a better quality coverage system that results in improved symmetry with the opposite hemi-thorax (Figure 6).

The palpation of the flap in the new site is similar in consistency to a normal breast. This flap is the only option that allows patients to achieve this result. No other flaps achieve a consistency that is as breast-like as the omentum.

\section{DISCUSSION}

All recent studies of laparoscopically harvested omentum flap procedures have shown that they result in shorter

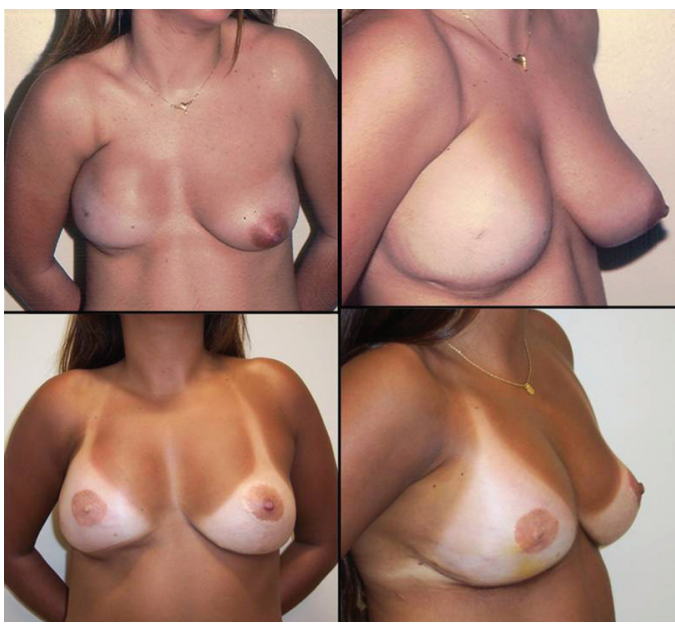

Figure 5 - Top: A Poland's syndrome patient missing the right breast who was treated with a tissue expansor and prosthesis and has an unpleasant transverse sulcus in the axillary pillar, an infraclavicular depression and an anomalous breast contour. Bottom: The same patient after a laparoscopically harvested omentum flap transposition to the right side that covers the prosthesis and conceals the infraclavicular depression and the anomalous breast contour. A mastopexy was performed on the opposite side in order to achieve a symmetric result.

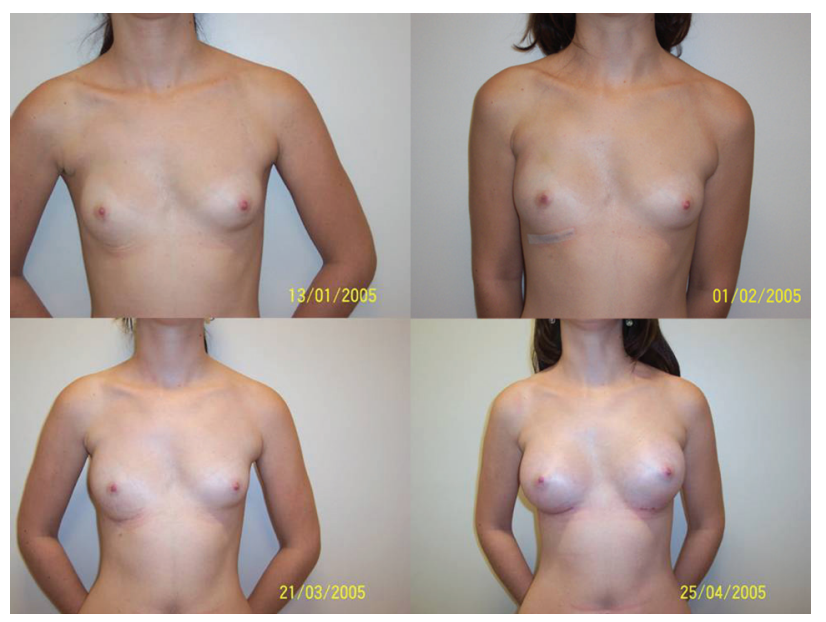

Figure 6 - A patient with Poland's syndrome on the right side. Nineteen days after the omentum flap transposition, it is possible to see the beginning of the omentum's growth in the lateral portion of the breast. Two months after omentum flap transposition only, the right breast had doubled in size, becoming bigger than the left breast. In the last picture, the right side has received a $200 \mathrm{cc}$ high-profile implant while the left side has received a 225 cc low-profile implant.

hospital stays, fewer complications, and a faster return to normal life when compared with open procedures. ${ }^{9-15}$

The excellent outcomes obtained with the omentum flap treatment of breast cancer patients were the main reason this technique was used in the treatment of Poland's syndrome.

Numerous treatment alternatives have been proposed to correct the most important deformities caused by this syndrome, including handmade expanders and prostheses, latissimus dorsi flaps and rectus abdominals muscle flaps, but all have offered only a partial correction of the 
deformities with poor aesthetic results..$^{5-8}$ While these other options offer breast volume, they do not have the malleability of the omentum flap, which permits the repair of special aesthetic details like the transverse skin fold in the anterior axillary pillar and the infra-clavicular depression. A laparoscopically harvested omental flap works much better than a fat graft, which will loose significant volume over time. In contrast, the omentum achieves sufficient volume with a single procedure without postoperative absorption and the corresponding loss of volume in the transplanted tissue, and it can even grow.

Utilization of the omentum flap, in our experience, offers people with these deformities the possibility of excellent cosmetic results. ${ }^{9,12}$

The omentum has been utilized in reconstructive surgery for more than a hundred years. In 1888, Senn employed it to protect an intestinal anastomosis, ${ }^{16}$ while in 1963, Kirikuta described the use of the great omentum as a flap in cases of breast cancer surgery. ${ }^{17}$

In 1972, McLean and Buncke described the omentum free flap, ${ }^{18}$ and in 1976, Arnold and Jurkiewicz used a pedicled omentum for reconstruction of the chest wall, and in two patients with Halsted mastectomies, they used a one-stage reconstruction using the transposed omentum to cover a silastic gel prosthesis and to support an overlaid skin graft. ${ }^{19}$ The laparoscopic harvesting of the omentum was carried out for the first time by Saltz in 1993 in order to repair soft tissue defects in the knee. ${ }^{10}$

In 1996, Goes applied the laparoscopically harvested omentum flap to breast reconstruction after a skin-sparing periareolar mastectomy by opening the abdominal cavity in the epigastrium at the end of the procedure to transfer the omentum from the abdominal cavity to the thoracic region. ${ }^{11}$ In the same year, Costa presented a totally closed video laparoscopic procedure where the flap was dissected in the abdominal cavity and transposed through a subcutaneous tunnel to the thoracic wall, and also used the technique to treat breast cancer patients. ${ }^{12}$

Costa utilized the omentum flap to treat Poland's syndrome deformities for the first time in $1998 .{ }^{9}$

The results from this group of patients demonstrate that use of the omentum flap ameliorates the thoracic wall and breast deformities caused by Poland's syndrome and gives superior outcomes when compared to other reconstructive options. The advantages of the omentum flap are numerous and significant: it is extremely malleable, it adapts easily to irregular surfaces, and it has a long and reliable vascular pedicle. The flap measures approximately $25 \times 35 \mathrm{~cm}$ and its volume varies according to patient size. ${ }^{20,21}$ In the first six months after the procedure, the omentum flap presents variable growth that needs to be considered when planning the repair of the deformity.

Other important advantages include the flap's large absorption capacity, which reduces the postoperative time period during which drains are needed, since the flap helps absorb the lymphatic fluid that results from lymph node dissection. The use of laparoscopy to harvest the flap offers minimal insult to the abdominal wall and ensures a short and comfortable postoperative recovery period. ${ }^{13-15}$ Finally, the resulting consistency of the tissue is very similar to the contra-lateral breast, which enables a more satisfactory repair of the anterior axillary pillar than any other reconstructive option.

A difficulty encountered with this technique is that it is not possible to precisely define the final omentum volume available while planning the reconstruction. The complementation of the volume and equalization with the contra-lateral breast may be done during the same surgery, but it works better four to six months later when it is possible to take into consideration the spontaneous growth of the flap that always occurs after its transposition (Figure 6). The skeletal deformities that come with this syndrome can be minimized, but when they are very severe, they may still distort the aesthetic appearance of the thoracic wall and breasts. In some cases, the outcome may call for another complementary procedure.

A review of all available literature on laparoscopically harvested omentum flaps indicates that there are no severe postoperative complications, a finding that is in agreement with the experience of our group.

Because of the great variability in the individual characteristics of the deformities resulting from Poland's syndrome, it is very difficult to establish objective parameters of comparison regarding aesthetic outcomes. Long-term evaluations may provide information about aesthetic results and patient satisfaction.

\section{CONCLUSION}

In conclusion, employing the omentum flap in the treatment of Poland's syndrome enables the anterior axillary pillar to be reconstructed and the infra-clavicular depression to be filled in. In addition, it provides a soft coverage system that is thick enough to conceal the silicone implants used for breast reconstruction, a feature that no other technique seems able to achieve. 


\section{REFERENCES}

1. Bainbridge LC, Wright AR, Kanthan R. Computed tomography in the preoperative assessment of Poland's syndrome. Br J Plast Surg. 1991;44:604-7.

2. Poland A. Deficiency of the pectoral muscles. Guy Hosp Rep. $1841 ; 6: 191-3$

3. Cobben JM, Robinson PH, van Essen AJ, van der Wiel HL, ten Kate LP. Poland anomaly in mother and daughter. Am J Med Genet. 1989;33:51921.

4. Perez Aznar JM, Urbano J, Garcia Laborda E, Quevedo Moreno P, Ferrer Vergara L. Breast and pectoralis muscle hypoplasia. A mild degree of Poland's syndrome. Acta Radiol. 1996;37:759-62.

5. Seyfer AE, Icochea R, Graeber GM. Poland's anomaly. Natural history and long-term results of chest wall reconstruction in 33 patients. Ann Surg. 1988;208:776-82.

6. Gatti JE. Poland's deformity reconstructions with a customized, extrasoft silicone prosthesis. Ann Plast Surg. 1997;39:122-30.

7. Marks MW, Argenta LC, Izenberg PH, Mes LG. Management of the chest-wall deformity in male patients with Poland's syndrome. Plast Reconstr Surg. 199;87:674-8; discussion 9-81.

8. Rintala AE, Nordstrom RE. Treatment of severe developmental asymmetry of the female breast. Scand J Plast Reconstr Surg Hand Surg. 1989;23:231-5.

9. Costa SS. Tratamento cirúrgico da síndrome de Poland com omento transposto por Videolaparoscopia. In: PedriniJL RA, Penczek F, editor. XI Congresso Brasileiro de Mastologia. Foz do Iguaçu- Paraná: XI Congresso Brasileiro de Mastologia; 1998. p. 186.

10. Saltz R, Stowers R, Smith M, Gadacz TR. Laparoscopically harvested omental free flap to cover a large soft tissue defect. Ann Surg. 1993;217:542-6; discussion 6-7.
11. Góes JCS. Immediate reconstruction after mastectomy using a periareolar approach with an omental flap and mixed mesh support Perspectives in Plastic Surgery. 1996;10:69-81.

12. Costa SS. Uso do omento livre retirado por videolaparoscopia para reconstrução de mama. In: Reconstrutiva AdVEdSBdM, editor. Anais do VIII Encontro da Sociedade Brasileira de Microcirurgia Reconstrutiva. Rio de Janeiro: Sociedade Brasileira de Microcirurgia; 1996. p. Vol1:5.

13. Cothier-Savey I, Tamtawi B, Dohnt F, Raulo Y, Baruch J. Immediate breast reconstruction using a laparoscopically harvested omental flap. Plast Reconstr Surg. 2001;107:1156-63; discussion 1164-5.

14. Ferron G, Garrido I, Martel P, Gesson-Paute A, Classe JM, Letourneur B, et al. Combined laparoscopically harvested omental flap with meshed skin grafts and vacuum-assisted closure for reconstruction of complex chest wall defects. Ann Plast Surg. 2007;58:150-5.

15. Zaha $H$, Inamine $S$, Naito $T$, Nomura $H$. Laparoscopically harvested omental flap for immediate breast reconstruction. Am J Surg. 2006;192:556-8.

16. Irons GB, Witzke DJ, Arnold PG, Wood MB. Use of the omental free flap for soft-tissue reconstruction. Ann Plast Surg. 1983;11:501- 7.

17. Kiricuta I. [The use of the great omentum in the surgery of breast cancer.]. Presse Med. 1963 5;71:15-7.

18. McLean DH, Buncke HJ, Jr. Autotransplant of omentum to a large scalp defect, with microsurgical revascularization. Plast Reconstr Surg. 1972;49:268-74.

19. Jurkiewicz MJ, Arnold PG. The omentum: an account of its use in the reconstruction of the chest wall. Ann Surg. 1977;185:548-54.

20. Arnold PG, Hartrampf CR, Jurkiewicz MJ. One-stage reconstruction of the breast, using the transposed greater omentum. Case report. Plast Reconstr Surg. 1976;57:520-2.

21. Das SK. The size of the human omentum and methods of lengthening it for transplantation. Br J Plast Surg. 1976;29:170-44. 